\title{
Compact Broadband Microstrip Triangular Antennas Fed By Folded Triangular Patch for Wireless Applications
}

\author{
Hossein Malekpoor ${ }^{1}$, and Mojtaba Shahraki ${ }^{2}$ \\ ${ }^{1}$ Department of Electrical Engineering, Faculty of Engineering, Arak University, Arak, 38156-8-8349, Iran \\ ${ }^{2}$ Faculty of Electrical and Computer Engineering, University of Sistan and Baluchestan, Zahedan, Iran \\ Corresponding author: Hossein Malekpoor(h-malekpoor@araku.ac.ir).
}

\begin{abstract}
This study presents two new designs of reduced size broadband microstrip patch antennas for ultrawideband (UWB) operation. The suggested antennas are configured by a folded triangular patch's feeding technique, Vshaped slot, half V-shaped slot and shorting pins. The shorting pins are applied at the edge of structures to miniaturize the size of the patches. The suggested design with the $\mathrm{V}$-shaped slot provides the measured impedance bandwidth $\left(\mathrm{S}_{11}<-10 \mathrm{~dB}\right)$ of 3.91-12 GHz (101.7\%) for broadband application. In the suggested design with the V-shaped slot, the wide bandwidth with an acceptable size reduction is achieved. By introducing a suggested half design with the half V-shaped slot, the impedance bandwidth of the proposed half structure is improved from 4 to $17.22 \mathrm{GHz}$. The half design includes a measured impedance bandwidth of $124.6 \%$ with reduced size of more than $93 \%$ compared to the corresponding full design and an enhanced measured bandwidth of $23 \%$. The obtained radiation and impedance results show that the suggested designs are applicable for wideband operation. The prominent advantages of the proposed designs include miniaturized sizes, wide bandwidths and stable radiation patterns, whereas their major limitation is a more complex fabrication. Besides, the effects of some basic concepts and surface currents on the suggested structures are investigated to explain their broadband performance.
\end{abstract}

INDEX TERMS Half V-shaped slot, Microstrip antenna, UWB, Wideband.

\section{INTRODUCTION}

I $\mathrm{N}$ recent years, by increasing the development of modern wireless communication systems, satellite and missile applications, microstrip patch antennas have attracted a great deal of attention due to their charming specifications, such as low profile, light weight and ease of fabrication. However, a narrow impedance bandwidth of the microstrip antennas is regarded a significant issue in most studies. For this purpose, nowadays, miniaturized broadband patch antennas are considered in various technologies. Introducing UWB technology by Federal Communication Commission (FCC) in 2002 and allocating the frequency range 3.1-10.6 GHz has been attracted the researchers' consideration exclusively on this matter [1], [2].

Due to the development of the wireless systems and integrated circuit technologies, compact microstrip antennas with enhanced bandwidth have been significantly noticed in many types of research. Various designs have been proposed in the kinds of literature to reduce the size of microstrip patch antennas [3]-[8]. A meandered patch or ground plane is presented in [3]. In such schemes, creating the slots into the patch and ground plane lengthen the current path and reduce the operating frequency. Also, realizing a shorting pin/wall
[4] is a useful method to prolong the effective electric length of the patch. The Shorting pins significantly reduce the frequency of antennas and they result in a quarterwavelength structure. However, it affects the performance of the antenna and may slightly deteriorate the radiation patterns for each polarization. Various techniques in previous works have been developed to improve the impedance bandwidth of microstrip antennas [9]-[19]. For this purpose, utilizing the impedance matching networks [9], [10] and inserting the slots into the patch are taken into consideration as two common methods [11]-[13]. Various shapes of slots on the patch such as U-shaped-slot patches [14], [15], E-shaped patches [16], [17] and V-shaped patch [18], [41] provide a wide bandwidth up to $33 \%$. By fulfilling the L-shaped probe feeding system, the impedance bandwidth is impressively improved [20], [21]. Other efficient methods of the bandwidth enhancement include the shorted-patches [22], [23] and applying shorting pins [24]. Also, some research works have been provided in order to attain the broadband microstrip antennas by applying the stacked patches [25][30]. In [25], stacked patch antennas are parasitically coupled and provide a larger bandwidth than a single patch antenna. This design provides $100 \%$ bandwidth from $23.9-72.2 \mathrm{GHz}$. 
Recently, momentous studies have been done to widen importantly the operation bandwidth with good impedance matching using a folded-patch feed method [31]-[40]. A Ushaped slot patch antenna fed by a folded patch with a shorting wall is realized to show an impedance bandwidth of 53.54\% [31]. A microstrip antenna fed by a folded patch with an E-shaped patch introduces UWB structure and its bandwidth further improves to $73.78 \%$ [33]. Also, by applying this feeding approach, a wideband stacked patch antenna (almost 90\%) with the E-shaped shape is reported in [34]. In [36], a simple broadband circularly polarized antenna for ultra-high frequency (UHF) RF identification (RFID) readers is proposed using a folded plate to cover the frequency range of $800-970 \mathrm{MHz}$. In the last studies, flexible microstrip antennas are introduced for wireless applications [42] and [43].

In this article, broadband shorted patch antennas fed by folded-patch with the V-shaped slot and the half V-shaped slot are reported. By using a half triangular patch on the half V-shaped feeding system, a miniaturized patch antenna for UWB wireless communications is obtained. Initially, a triangular patch antenna with a compact size of $17.5 \mathrm{~mm}$ $\times 17.5 \mathrm{~mm} \times 17.5 \mathrm{~mm}$ with a folded-patch feeding method and a V-shaped slot is presented to include the impedance bandwidth of $101.7 \%$ in $3.91-12 \mathrm{GHz}$ for $\mathrm{S}_{11}<-10 \mathrm{~dB}$. Subsequently, by utilizing a half structure with a foldedpatch feeding method and a half V-shaped slot, the UWB patch antenna is also achieved. It provides an impedance bandwidth of $124.6 \%$ in $4-17.22 \mathrm{GHz}$. By introducing the half triangular patch antenna compared to the full structure, the size of the patch is considerably reduced. Moreover, it is found that the impedance bandwidth, radiation patterns and gain of the half structure are comparable to the corresponding full structure. Finally, it can be comprehended that the radiation patterns indicate at least a change over the operating band for two structures.

\section{ANTENNAS DESIGNS AND STRUCTURES}

In this section, the structures of suggested designs are demonstrated for full and half patch antennas. The suggested antennas are excited by a coaxial probe $(50-\Omega$ SMA connector) due to its easy fabrication and low spurious radiation. But, it leads to a narrow impedance bandwidth because of its high $\mathrm{Q}$ factors. As usual, employing the thick substrate with air dielectric constant substrate leads to a broader bandwidth. For thick microstrip patch antennas with probe feeding, the effect of the inductive reactance of the lengthy probe is a crucial problem to gain a great impedance matching across a wide operating bandwidth. In order to solve this problem and enhancing the bandwidth with better impedance matching, a new feeding approach, as the folded-patch feed technique has been proposed [31]-[34]. It reduces the self-generated inductive reactance caused to the long probe. Thus, the impedance bandwidth is impressively enhanced.

3D View
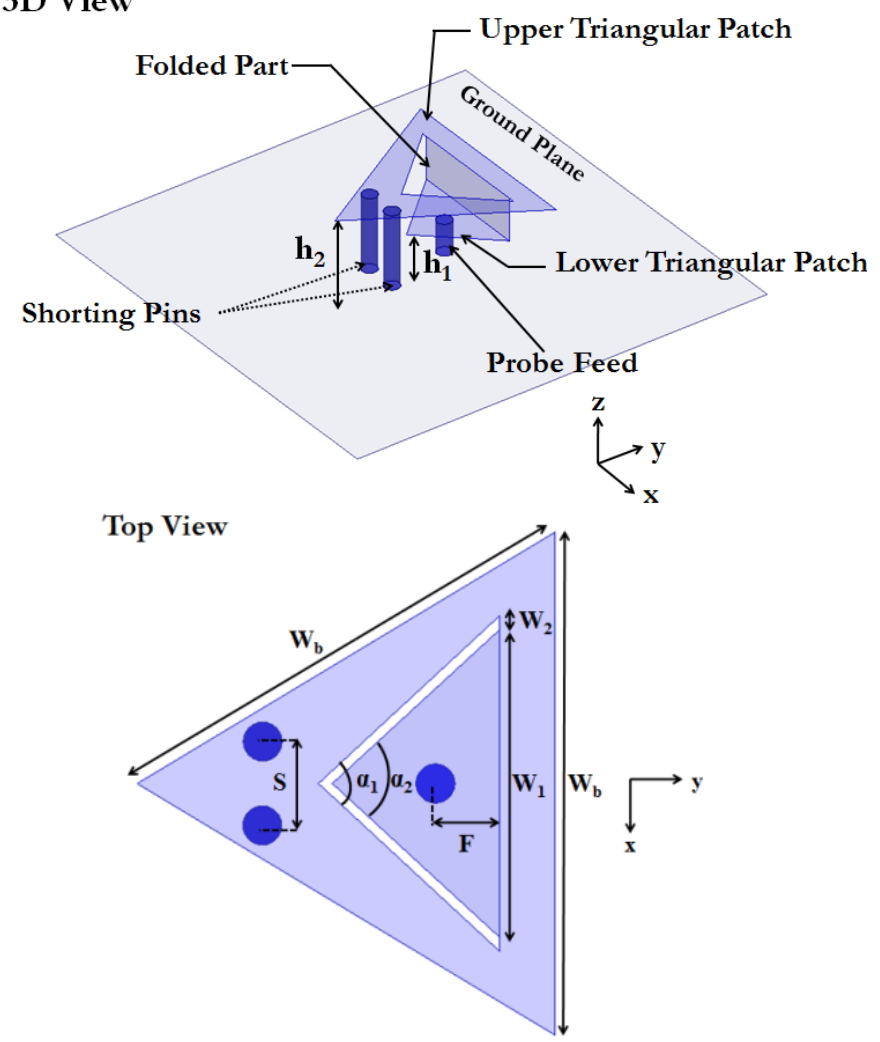

Side View

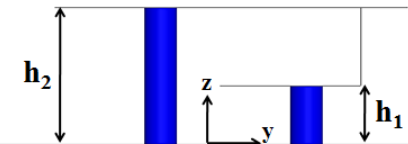

FIGURE 1. Structure of the suggested triangular patch antenna with $\mathrm{V}$ shaped slot.

\section{A. Full Structure}

The configuration of the suggested patch antenna with the $\mathrm{V}$-shaped slot is shown in Fig. 1. This antenna contains a triangular patch as an upper patch, shorting pins and a lower triangular patch which through a bent section joins to the upper patch. The shorting pins and probe maintain the upper triangular patch with the dimensions of each side of $17.5 \mathrm{~mm}$ above the rectangular ground plane of $70 \mathrm{~mm} \times 70$ $\mathrm{mm}$ at the height of $h_{2}$ with air substrate. The distance between the optimal feed position and the vertex of the lower triangular patch is $3.7 \mathrm{~mm}$. The coaxial probe is located in the midline of the patch on the y-axis. The upper patch is shorted at the one edge to the ground plane by two pins with a diameter of $1.4 \mathrm{~mm}$. The distance between two pins is selected $\mathrm{S}=3 \mathrm{~mm}$. The lower triangular patch with height $h_{l}$ is designed to decrease the probe length, whereas the height of $h_{2}$ is chosen $7 \mathrm{~mm}$. Thus, a miniaturized antenna with a reduced probe inductance is gained to make a wide bandwidth. According to Fig. 1, the triangular aperture on the upper patch with optimized angle $\alpha_{1}$ is utilized to expand the bandwidth. Also, angle $\alpha_{2}$ on the triangular lower patch is designed so that the maximum 
bandwidth with better impedance matching can be achieved.

3D View
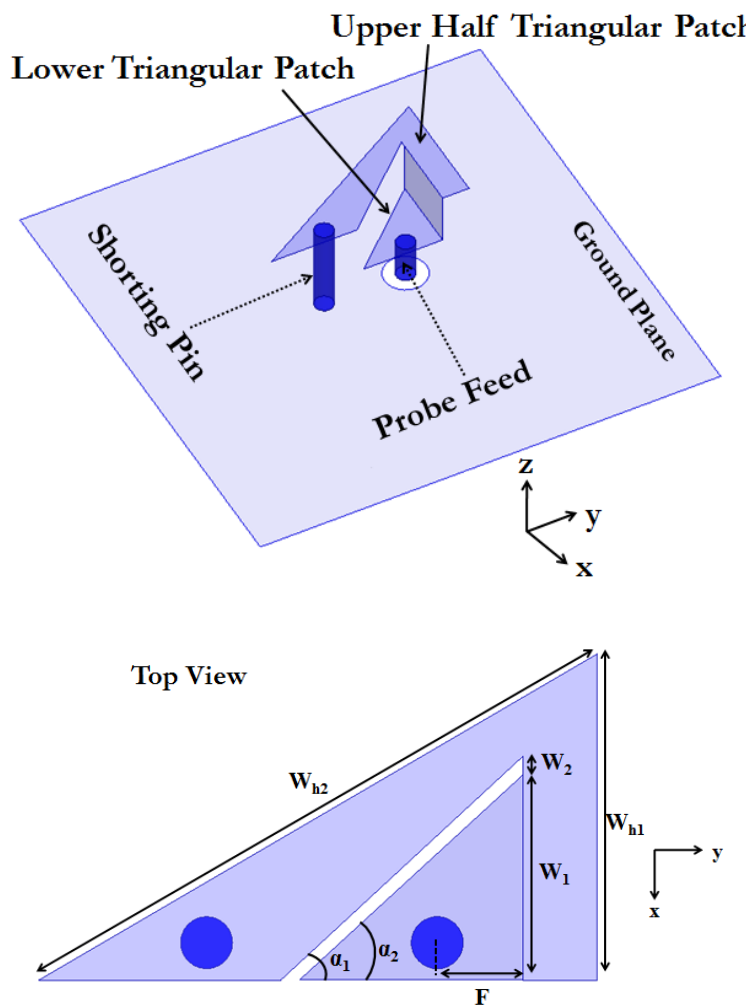

FIGURE 2. Structure of the suggested half triangular patch antenna with half V-shaped slot.

Based on the transmission line model for the rectangular radiating patch, the basic width $(W)$ and length $(L)$ of the patch at the resonant frequency are determined using equations (1)-(4) [2]:

$W=\frac{\lambda_{0}}{2 \sqrt{\frac{\varepsilon_{r}+1}{2}}}$

$L=\frac{c}{\Gamma}-2 \Delta L$

$\varepsilon_{\text {eff }}=\frac{\varepsilon_{r}+1}{2}+\frac{\varepsilon_{r}-1}{2}\left(\frac{1}{\sqrt{1+12 \frac{h}{W}}}\right)$

$\Delta L=0.412 h\left(\frac{\left(\varepsilon_{\text {eff }}+0.3\right)\left(\frac{W}{h}+0.264\right)}{\left(\varepsilon_{\text {eff }}-0.258\right)\left(\frac{W}{h}+0.813\right)}\right)$
Where, Eeff, $h$ and $\Delta L$ are effective permittivity coefficient, thickness and additional length due to fringing fields, respectively.

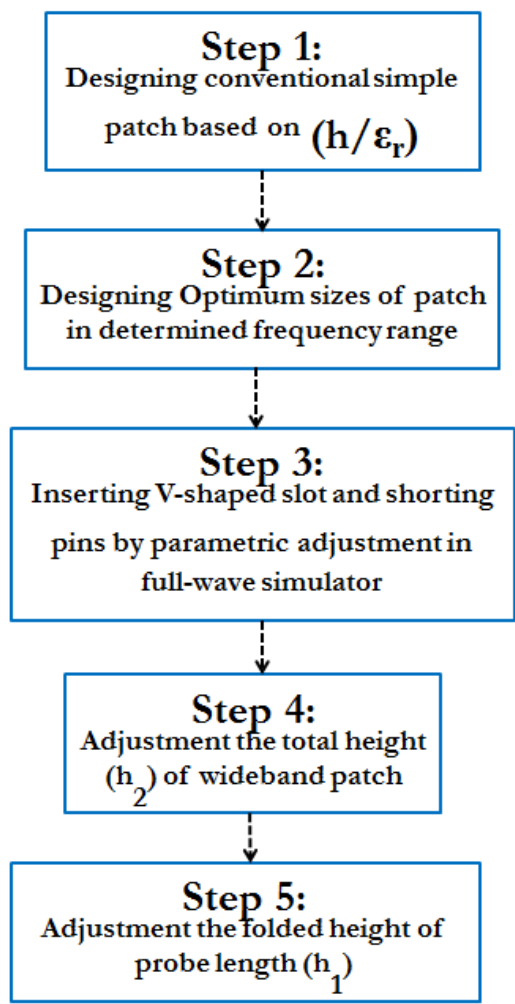

FIGURE 3. Flow chart of the design process for the proposed structure.

The basic width and length are designed based on the equations (1)-(4) for determined operating frequency at UWB band. In this case, air dielectric constant substrate, $\varepsilon_{r}=1$ is considered. The optimum sizes of the proposed patch such as a V-shaped slot, shorting pins, probe length and total height of the patch are optimized by full-wave simulator with the parametric study. According to Fig. 3, the flow chart of the design process is introduced in the five steps. It shows the five steps to attain an optimum proposed design for UWB operation.

\section{B. Half Structure}

The configuration of the suggested half triangular patch antenna is shown in Fig. 2. This antenna contains a half triangular patch as an upper patch, a shorting pin and a triangular lower patch which through a bent section joins to the upper patch. The half structure is maintained by pin and probe that connect the upper half triangular patch with dimensions of $8.75 \mathrm{~mm} \times 17.5 \mathrm{~mm}$ to the ground plane. The coaxial probe is located in the midline of the patch on the $y$ axis. The feed point is placed on the edge of the lower triangular patch with a distance of $3.7 \mathrm{~mm}$ from the vertex of the triangular. The upper patch is shorted at the one edge to the ground plane by one pin with a diameter of $1.4 \mathrm{~mm}$. The lower triangular patch with height $h_{l}$ is designed to decrease the probe length, whereas the height of $h_{2}$ is 
chosen $7 \mathrm{~mm}$. It should be noted that the half structure compared with the corresponding full structure, provides a considerable size reduction with a great impedance bandwidth for UWB operation. Various dimensions of the half V-shaped slot patch antennas can be considered for wideband operation.

Moreover, the optimized dimensions of the bent section and the lower triangular patch are major segments for creating upper resonances to widen the bandwidth of suggested designs. The shorting pins, which are loaded on one side of the upper patches present a conventional $\lambda / 4$ shorted patch. These pins affect the lowering of the frequency of the antennas. Hence, the effective electrical length of this patch increases and consequently, appropriate miniaturization and wider impedance bandwidth obtains. The recommended feeding technique is applied for various geometrical sizes of the triangular patch. The values of design parameters for the two suggested antennas are addressed in Table I. The suggested antennas are realized with a copper plate with $0.2 \mathrm{~mm}$ thickness and it is maintained by the probe and shorting pins. The performance and wideband mechanism based on surface current distributions and radiation patterns are described and discussed in section III. The fabricated antennas are illustrated in Fig. 4.
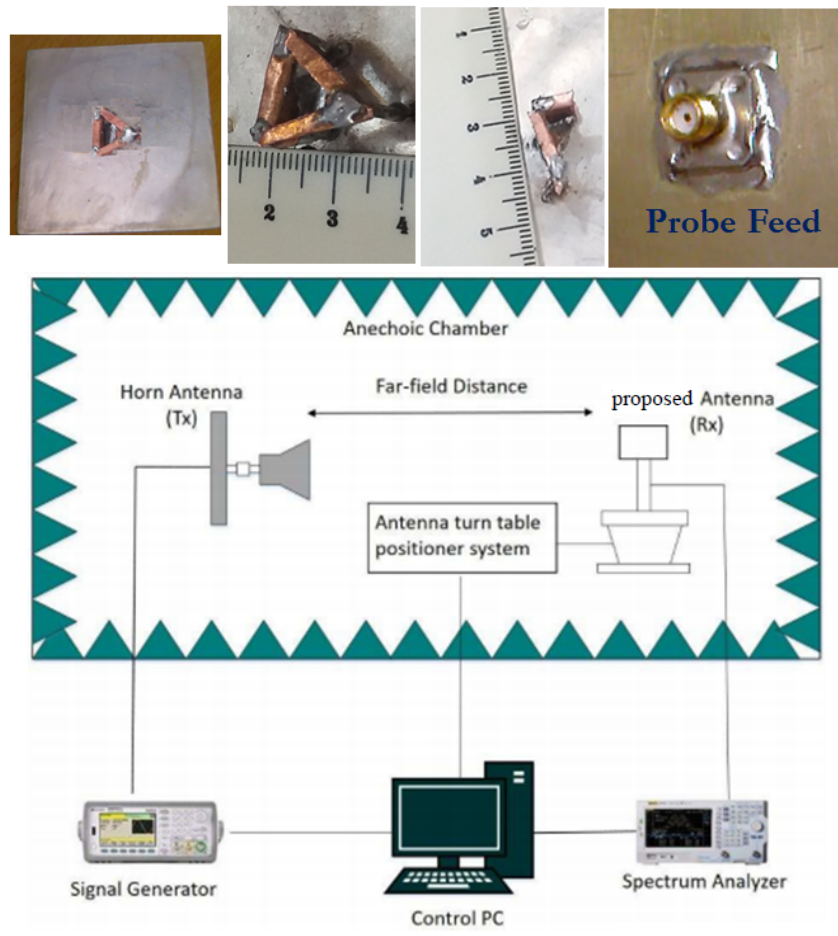

\section{EXPERIMENTAL AND SIMULATION RESULTS WITH DISCUSSIONS}

The computational results are managed with the fullwave software of Ansoft High-Frequency Structure Simulator (HFSS). The measured results have an acceptable accord with simulation results by applying a finite ground plane. The simulated and measured S-parameters of the suggested full design with the $\mathrm{V}$-shaped slot are exhibited in Fig. 5. This figure shows that the antenna operates in 3.91-12 $\mathrm{GHz}$ for $\mathrm{S}_{11} \leq-10 \mathrm{~dB}$ with a measured relative bandwidth of $101.7 \%$. It is observed in Fig. 5 that the suggested structure operates for the UWB application. It is obvious that by achieving the reduced size, the bandwidth 
is widened for UWB operation. Also, Fig. 5 shows the reflection coefficient of the full design without shorting pins includes $6.55-12.48 \mathrm{GHz}(62.32 \%)$. Thus, it is concluded that by using two pins at one end of the upper patch, the bandwidth progresses to $39.38 \%$.

Fig. 6 indicates the simulated and measured reflection coefficients of the half structure presented in Fig. 2. It is well seen that the suggested half antenna with the half $\mathrm{V}$ shaped slot operates from $4 \mathrm{GHz}$ to $17.22 \mathrm{GHz}$ with measured $-10 \mathrm{~dB}$ impedance bandwidth of $124.6 \%$. The suggested half design compared with the full structure introduces a bandwidth enhancement of almost $23 \%$. Also, according to Fig. 6, the reflection coefficient of the half design without the shorting pin includes the frequency range of $6.6-17 \mathrm{GHz}(88.14 \%)$.

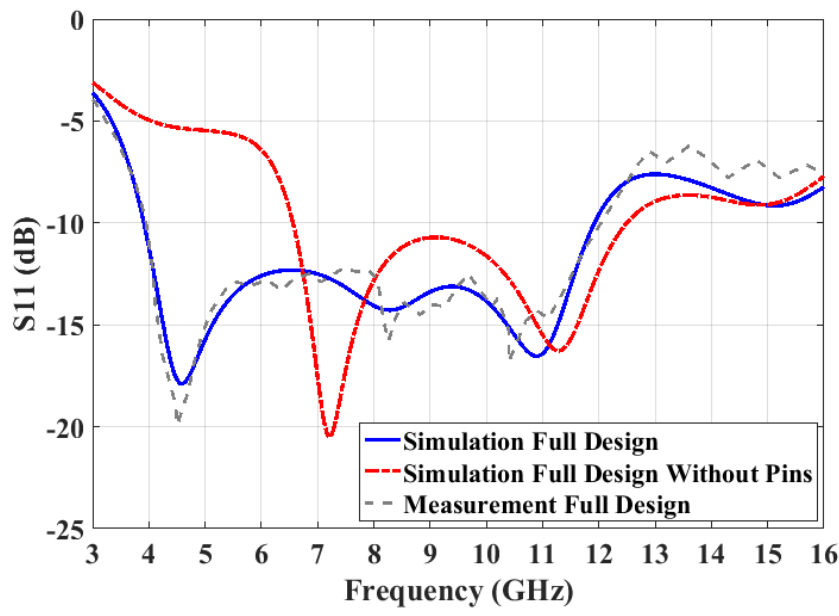

FIGURE 5. Measurement and simulation results of S-parameters of suggested full structure with V-shaped slot.

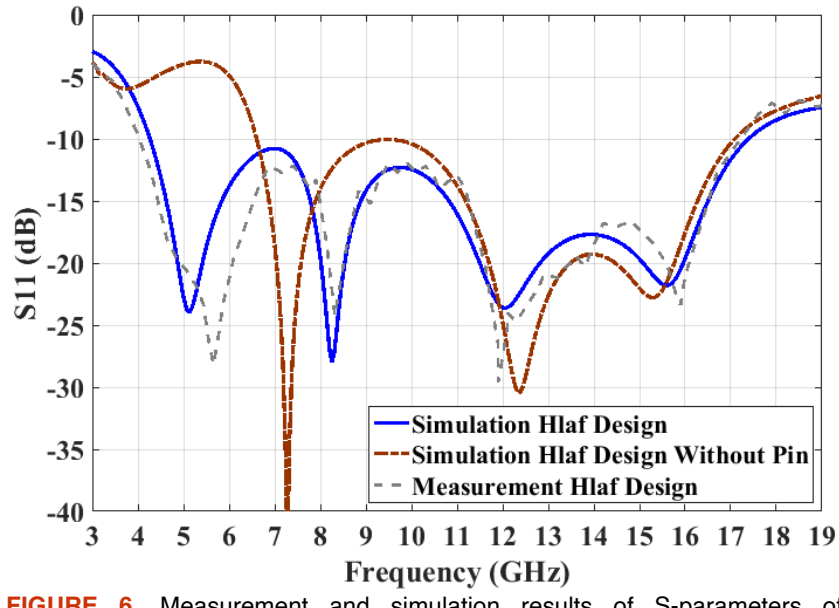

6. Measurement and simulation rest

Three lengths of triangle sides and the total height of the patch of full design with the V-shaped slot are $0.228 \lambda_{L}$, $0.228 \lambda_{L}, 0.228 \lambda_{L}$ and $0.0912 \lambda_{L}$, respectively $\left(\lambda_{L}\right.$ is the wavelength at the lower frequency). Whereas, three lengths of half triangle sides and the total height of the patch of the half structure are $0.233 \lambda_{L}, 0.2 \lambda_{L}, 0.116 \lambda_{L}$ and $0.093 \lambda_{L}$, respectively. Therefore, by introducing the half $\mathrm{V}$-shaped slot technique in the suggested half design, $93.32 \%$ size reduction is provided with respect to the full design with the V-shaped slot.

To investigate the effect of the height of lower patch $h_{l}$ for two suggested designs refer to Fig. 7. It plots the variations of the probe lengths. It illustrates when the probe length increases, the impedance bandwidth decreases. In order to gain wideband operation, the optimized values of probe lengths $h_{1}$ for full and half antennas are opted $3 \mathrm{~mm}$. To obtain the maximum bandwidth with good impedance matching, the value of $h_{2}$ for two antennas is equal to $7 \mathrm{~mm}$.

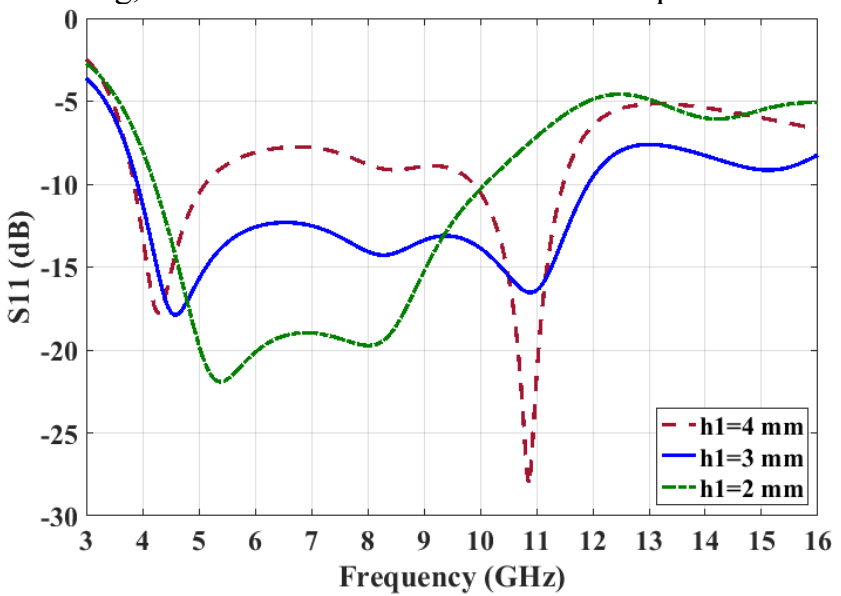

(a)

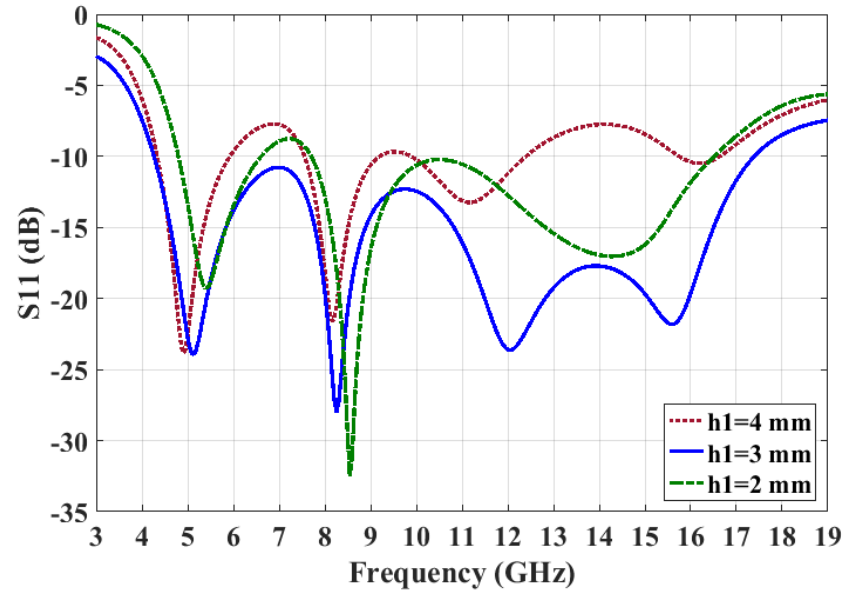

(b)

FIGURE 7. S-parameters for various values of $h_{1}$ (a) full design (b) half design. 


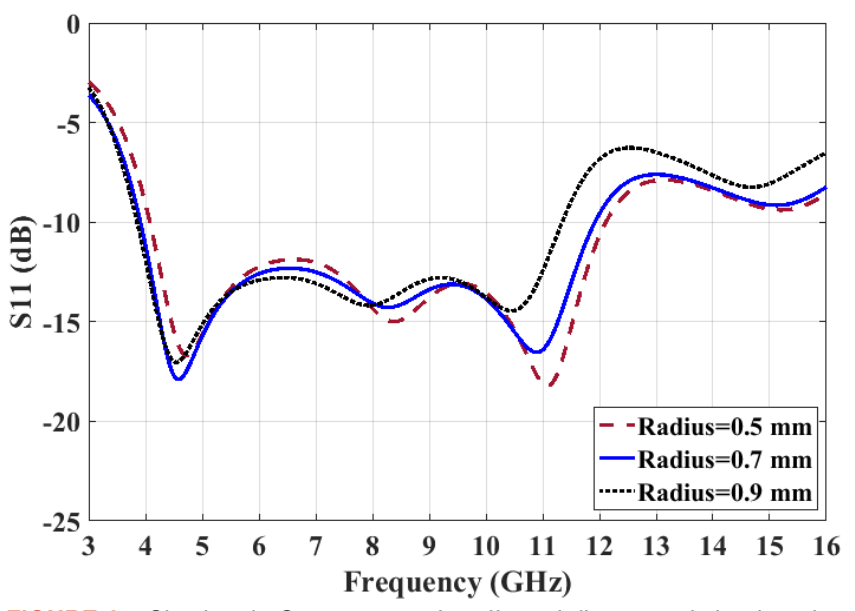

FIGURE 8. Simulated S-parameters for effect of diameter of shorting pins in the full design.

It is also concluded that by reducing the probe length from an optimized value, the capacitive effects overcome and consequently a fewer impedance bandwidth attains.

Fig. 8 illustrates the effect of the diameter of the shorting pins, at the one end of the proposed antenna. With an increase in the diameter of pins, the operating frequency reduces to lower frequencies. This is due to the fact that the pins lead to lengthening surface current on the patch. Hence, the electrical length of the patch is considerably increased and consequently, an appropriate miniaturization obtains until diameter reaches the optimum value. It is obviously seen that for a radius of $0.7 \mathrm{~mm}$, an optimum result of S-parameter is attained for wide bandwidth with excellent impedance matching.

The xz-plane (H-plane) and yz-plane (E-plane) radiation patterns at two-dimensional orthogonal planes for the suggested design with the V-shaped slot are demonstrated in Fig. 9. Also, the measurement and simulation results of radiation patterns in the xz-plane (H-plane) and yz-plane (E-plane) for the suggested half design are plotted in Figs. 10. It is well found out that a suitable agreement between the measured and simulated results is appointed. Simultaneously, the suggested antennas present acceptable unidirectional radiation patterns. The cross-polarization in the xz-plane compared to the yz-plane shows a higher level. The feed location on the y-axis and the asymmetry of structures can produce higher-order modes and consequently enhances the cross-polarized level. The obtained radiation patterns over the operating bandwidth don't drastically change for different frequencies. Moreover, shorting pins by introducing the asymmetry of the structure can affect the increase of the contribution of the cross-polarized radiation.

According to the gain of the suggested structures in Fig. 11, the maximum gain of the suggested full design within the operational bandwidth is $5.1 \mathrm{dBi}$. Moreover, the maximum gain of the suggested half design over the operational frequency band is $4.8 \mathrm{dBi}$. Thus, it shows that the gain of the half structure is comparable to the corresponding full structure.
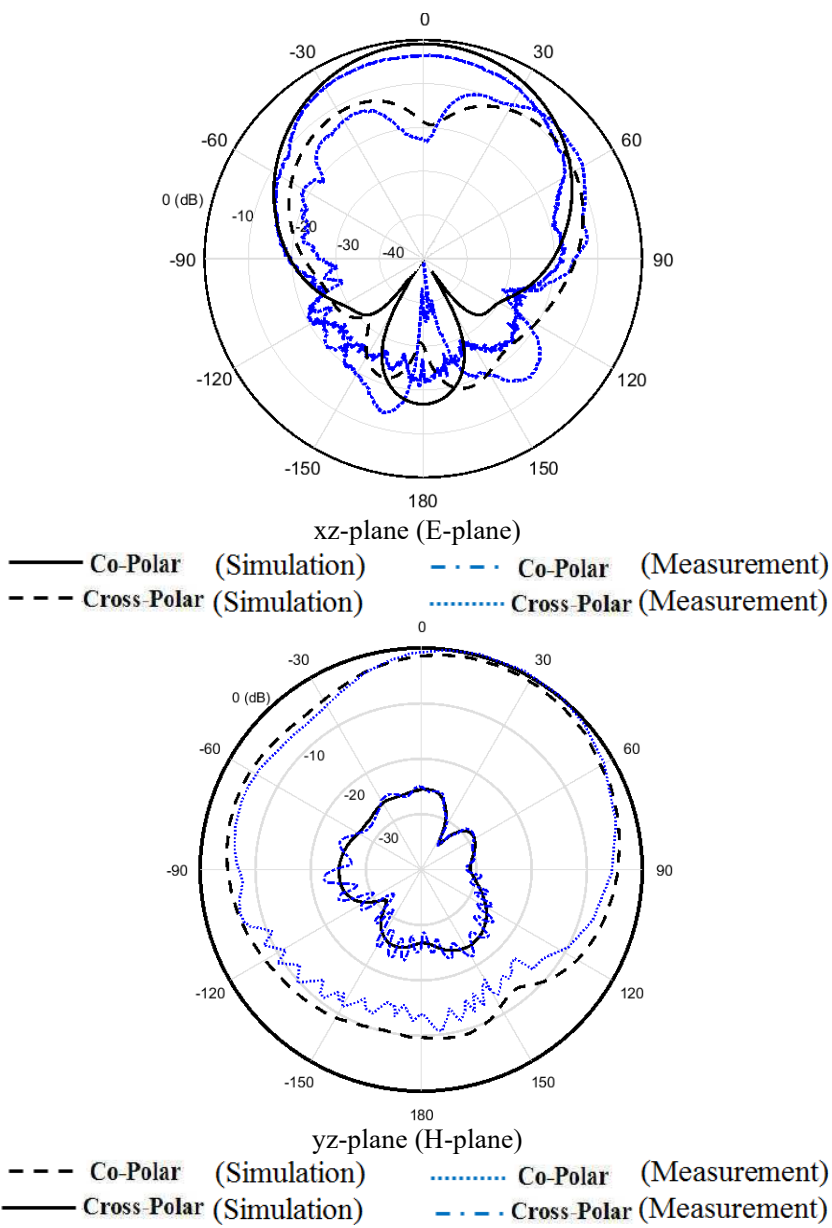

(a)

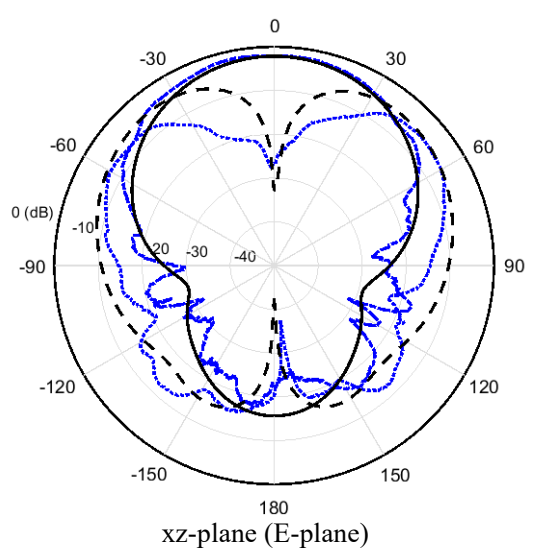

Co-Polar (Simulation) - - Co-Polar (Measurement) - - - Cross-Polar (Simulation) …...... Cross-Polar (Measurement) 


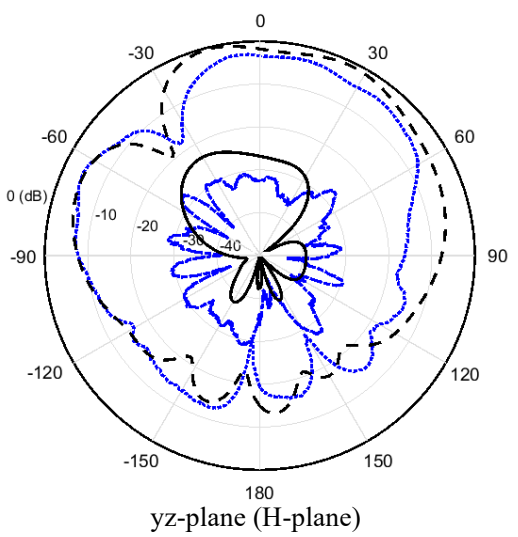

- - Co-Polar (Simulation)

Co-Polar (Measurement)

Cross-Polar (Simulation)

- - - Cross-Polar (Measurement)

(b)

FIGURE 9. Measurement and simulation results of radiation patterns of the suggested full design with $\mathrm{V}$-shaped slot at (a) $4.5 \mathrm{GHz}$ (b) $10.9 \mathrm{GHz}$.

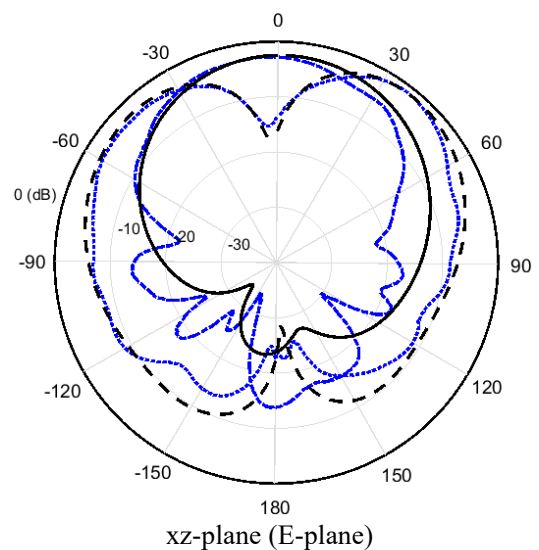

xz-plane (E-plane)

Co-Polar (Simulation) - - C Co-Polar (Measurement) - - - Cross-Polar (Simulation) ……... Cross-Polar (Measurement)

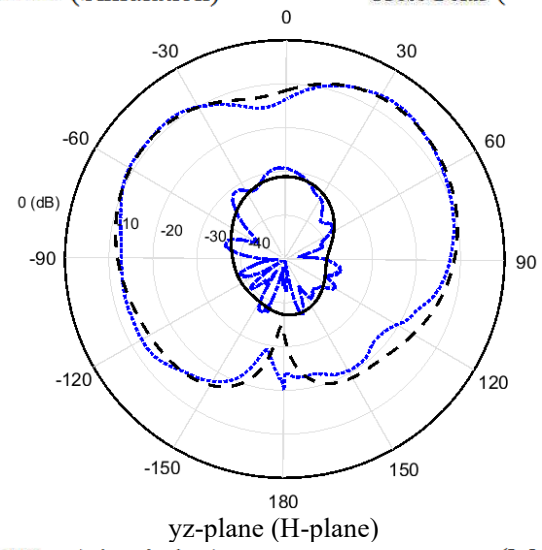

- - - Co-Polar (Simulation)

(H-p.n.

Cross-Polar (Simulation)

(a)

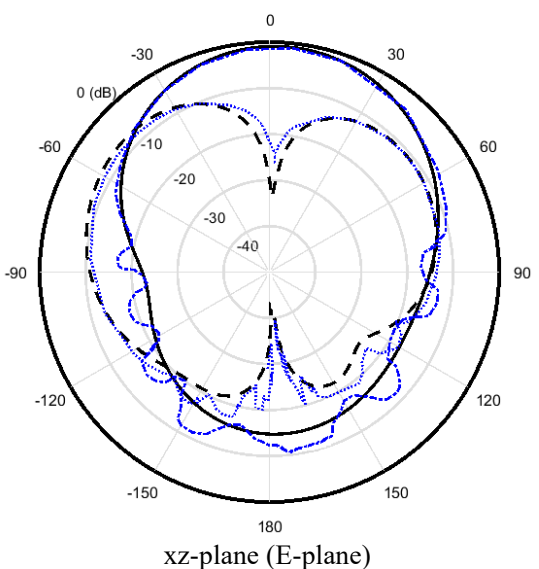

C Co-Polar (Simulation) - - - Co-Polar (Measurement) - - - Cross-Polar (Simulation) ……... Cross-Polar (Measurement)

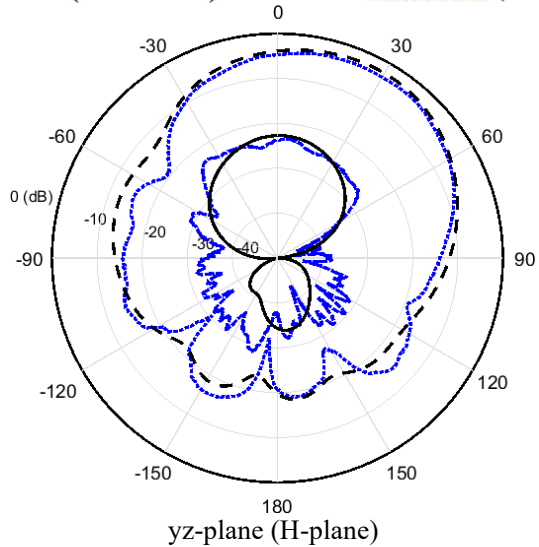

- - Co-Polar (Simulation) .......... Co-Polar (Measurement) Cross-Polar (Simulation) (b)

FIGURE 10. Measurement and simulation results of radiation patterns of the suggested half design with half V-shaped slot at (a) $5 \mathrm{GHz}$ (b) $15.5 \mathrm{GHz}$.

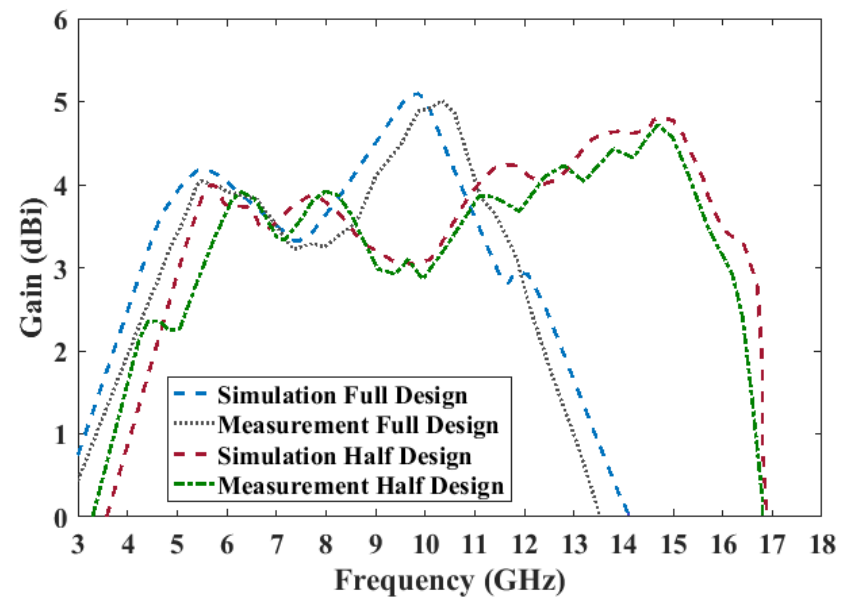

FIGURE 11. Measurement and simulation results of gains of the suggested antennas. 


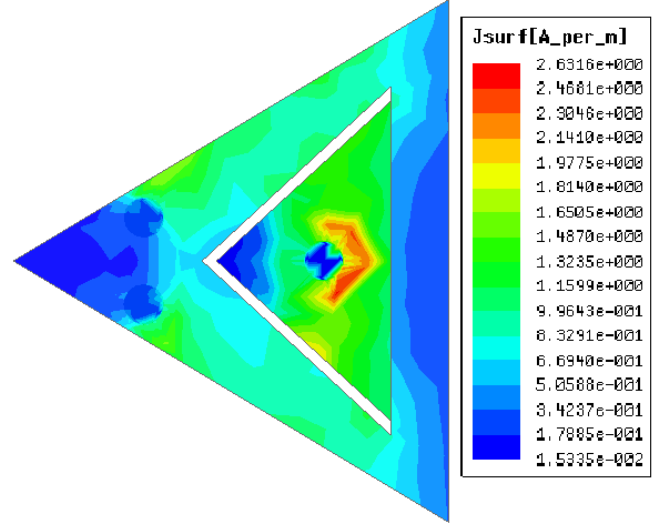

(a)

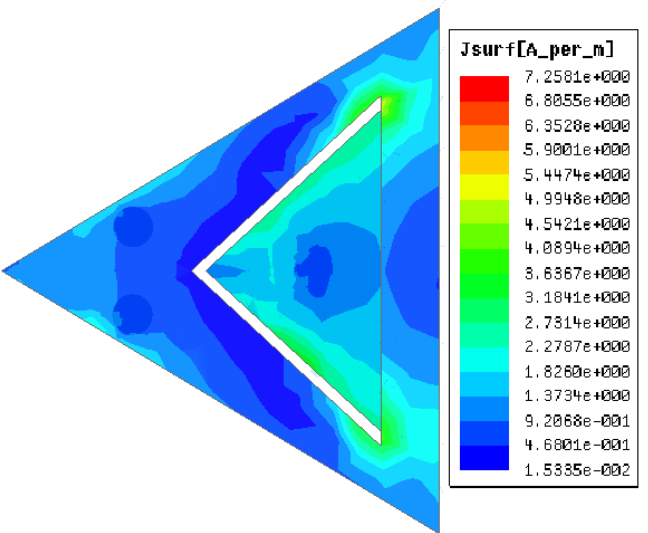

(b)

FIGURE 12. Surface current density on the patch of the suggested full design at: (a) 4.5 (b) $10.9 \mathrm{GHz}$.

The surface current density on the patch at two resonances of the suggested full design is determined in Fig. 12. As shown in Fig. 12 (a) at the resonance of 4.5 $\mathrm{GHz}$, the current density is concentrated close to the two pins, around the $\mathrm{V}$-shaped slot and the lower triangular patch. Thus, it can be considered that two shorting pins are effectively determined the first resonance at lower frequencies. Also, it is confirmed by Fig. 5 that by using pins at the one end of the triangular patch, a new resonance occurs at lower frequencies to achieve a wider bandwidth and more size reduction. At the higher resonances of 10.9 $\mathrm{GHz}$, the current density focuses on the bent section, lower triangular patch and the section of the upper patch joined to bent part. Fig. 13 shows the surface current density on the patch at three resonant frequencies of the suggested half design. It can be seen at three resonances of 4.9, 8.1 and 15.5 $\mathrm{GHz}$, the concentration of current distribution moves from the edge of the upper triangular patch to the folded part, half V-shaped slot and lower triangular patch. At the higher resonances of $15.5 \mathrm{GHz}$, the current density focuses on the lower patch, around the half $\mathrm{V}$-shaped slot and close to the bent section. Therefore, the shorting pins, V-shaped slot, half V-shaped slot and folded part play decisive roles in determining the various resonances of the suggested designs.
The comparative behavior of the suggested designs is depicted in Table II. It well presents the remarkable features of the suggested structures which include considerable size reduction and wider bandwidth. Two suggested designs compared with the designs with similar folded feeding system like [14], [33] and [34] introduce a broader bandwidth with more size reduction.

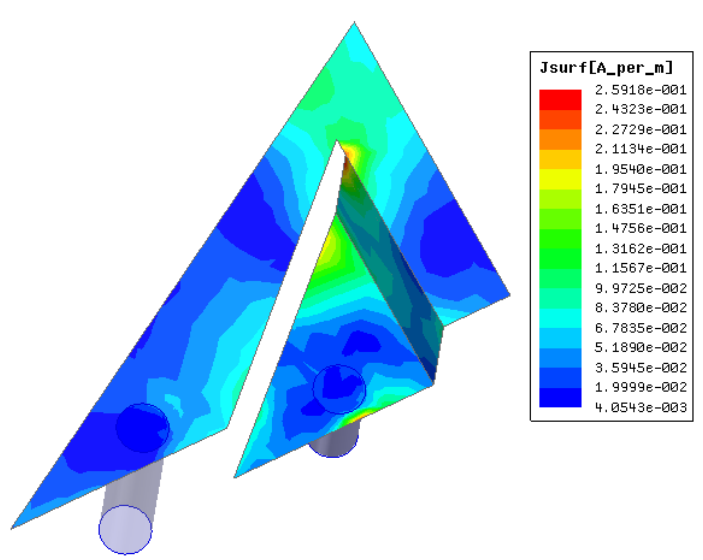

(a)

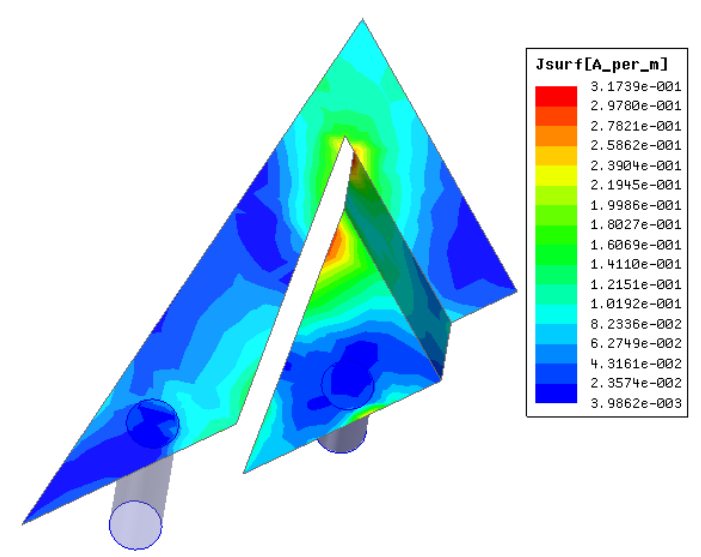

(b)

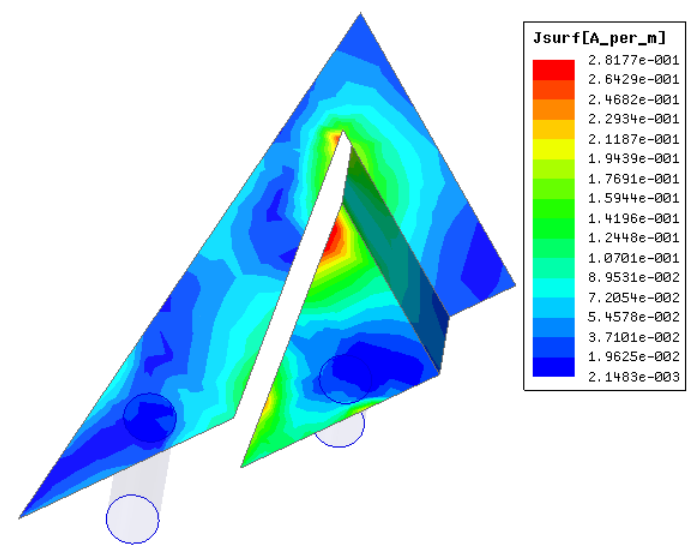

(c)

FIGURE 13. Surface current density on the patch of the suggested half design at: (a) 4.9 (b) 8.1 (c) $15.5 \mathrm{GHz}$. 
TABLE II. Comparison the performance of suggested designs with other studies

\begin{tabular}{|c|c|c|c|}
\hline & $\begin{array}{l}\text { Size of patch antenna } \\
\text { (width } \times \text { length } \times \text { total height) }\end{array}$ & $\begin{array}{c}\text { Impedance Bandwidth }\left(\mathrm{S}_{11}:-10 \mathrm{~dB}\right) \\
\text { and Maximum Gain }\end{array}$ & $\begin{array}{l}\text { Size reduction } \\
\text { (patch area) }\end{array}$ \\
\hline U-shaped slot antenna in [14] & $26.5 \mathrm{~mm} \times 31.5 \mathrm{~mm} \times 3 \mathrm{~mm}$ & $\begin{array}{l}\text { 4.82-6.26 GHz }(26.2 \%) \\
\text { Measured Gain: } 4.5 \mathrm{dBi}\end{array}$ & $13.62 \%$ \\
\hline UWB antenna in [37] & $14 \mathrm{~mm} \times 14 \mathrm{~mm} \times 1.6 \mathrm{~mm}$ & $\begin{array}{l}\text { 5.73-10.68 GHz (61.34\%) } \\
\text { Measured Gain: } 6 \mathrm{dBi}\end{array}$ & $25.8 \%$ \\
\hline $\begin{array}{l}\text { E-shaped antennas with } \\
\text { folded patch feed in [33] }\end{array}$ & $15 \mathrm{~mm} \times 15 \mathrm{~mm} \times 7 \mathrm{~mm}$ & $\begin{array}{l}\text { 3.96-8.59 GHz }(73.8 \%) \\
\text { Measured Gain: } 5 \mathrm{dBi}\end{array}$ & $145 \%$ \\
\hline $\begin{array}{l}\text { Stacked patch antennas fed } \\
\text { by folded patch in [34] }\end{array}$ & $15 \mathrm{~mm} \times 15 \mathrm{~mm} \times 10 \mathrm{~mm}$ & $\begin{array}{l}\text { 3.75-9.86 GHz (90\%) } \\
\text { Measured Gain: } 6.1 \mathrm{dBi}\end{array}$ & $152 \%$ \\
\hline UWB antenna in [39] & $24 \mathrm{~mm} \times 38.87 \mathrm{~mm} \times 1.6 \mathrm{~mm}$ & $\begin{array}{l}\text { 3.05-12.11 GHz }(100 \%) \\
\text { Measured Gain: } 5.21 \mathrm{dBi}\end{array}$ & $36.26 \%$ \\
\hline UWB design in [40] & $24.8 \mathrm{~mm} \times 30 \mathrm{~mm} \times 1.6 \mathrm{~mm}$ & $\begin{array}{l}\text { 2.7-10.5 GHz (113\%) } \\
\text { Measured Gain: } 4.1 \mathrm{dBi}\end{array}$ & $46.6 \%$ \\
\hline Suggested full design & $17.5 \mathrm{~mm} \times 17.5 \mathrm{~mm} \times 7 \mathrm{~mm}$ & $\begin{array}{l}\text { 3.91-12 GHz }(101.7 \%) \\
\text { Measured Gain: } 5.1 \mathrm{dBi}\end{array}$ & $90.2 \%$ \\
\hline Suggested half design & $8.75 \mathrm{~mm} \times 17.5 \mathrm{~mm} \times 7 \mathrm{~mm}$ & $\begin{array}{l}\text { 4-17.22 GHz (124.6\%) } \\
\text { Measured Gain: } 4.8 \mathrm{dBi}\end{array}$ & $183.5 \%$ \\
\hline
\end{tabular}

\section{CONCLUSION}

The Shorted patches with the folded triangular patch as the feeding techniques provide miniaturized broadband antennas for UWB operation. The full antenna design by applying the folded-patch feed with the V-shaped slot and two shorting pins introduces the impedance bandwidth from 3.91 to 12 $\mathrm{GHz}(101.7 \%)$. By applying the suggested feeding method at the half antenna design with the half V-shaped slot, a UWB patch antenna with reduced size is obtained. It shows a wide bandwidth of more than $124 \%$. The half antenna compared to the full design gains a broader bandwidth of $23 \%$ and more size reduction of $93 \%$. The remarkable characteristics of the presented antennas can point out the considerable miniaturization, wide bandwidth with comparatively simple structures, and low cross-polarization level in H-plane. Likewise, the surface current densities on the introduced patches are investigated for various resonances to describe the wideband performance of structures.

\section{REFERENCES}

[1] L. Kang, H. Li, X. Wang, and X. Shi, "Compact Offset Microstrip-Fed MIMO Antenna for Band-Notched UWB Applications", IEEE Antennas Wireless Propag. Lett., vol. 14, pp. 1754-1757, 2015.

[2] L. A, Wei., "Applications of ultra wideband".MS thesis, The University of Texas at Arlington, December 2006.

[3] H. D. Chen and Y. H. Tsao, "Low-Profile Meandered Patch Antennas for RFID Tags Mountable on Metallic Objects", IEEE Antennas Wireless Propag. Lett., vol. 9, pp.118-121, 2010.

[4] D. Guha, and Y. M. M. Antar, "Circular microstrip patch loaded with balanced shorting pins for improved bandwidth", IEEE Antennas Wireless Propag. Lett. vol. 5, pp. 217-219, 2006.

[5] Y. J. Wang, C. K. Lee, and W. J. Koh, "Single-patch and single-layer square microstrip antenna with $67.5 \%$ bandwidth", IEE Proc. Microw. Antennas Propag., vol. 148, pp. 418-422, 2001.

[6] Q. Q. Teruel, E. Pucci, and E. R. Iglesias, "Compact loaded PIFA for multi frequency applications", IEEE Trans. Antennas Propag., vol. 58, pp. 656-664, 2010.

[7] X. Sun, G. Zeng, H. C. Yang, and Y. Li, "A Compact Quadband CPW-Fed Slot Antenna for M-WiMAX/WLAN Applications" IEEE Antennas Wireless Propag. Lett., vol. 11, pp. 395-398, 2012.

[8] A. Kundu and A. K. Bhattacharjee, "Design of compact triple frequency microstrip antenna for WLAN/WiMAX applications", Microwave \& Opt. Tech. Lett., vol. 57, pp. 21252129,2015

[9] J. Zhang, H. Lan, M. Liu, and Y. Yang, "A wideband patch antenna with a pair of antisymmetric balun as differentially fed 
network," International Journal of RF and Microwave Computer-Aided Engineering, vol. 29, Is. 3, e21618, 2019.

[10] H. Zhang, L. Wang, H. Li, Y. Li, J. Y. Yin, and Y. Yin, "Lowprofile wideband patch antenna using double-tuned impedance matching," International Journal of RF and Microwave Computer-Aided Engineering, vol. 29, Is. 9, e21836, 2019.

[11] T. K. Saha, C. Goodbody ,T. Karacolak, and P. K. Sekhar, "A compact monopole antenna for ultra-wideband applications", Microwave \& Opt. Tech. Lett., vol. 61, pp. 182-186, 2019.

[12] C. Chunling, "Characteristic mode analysis and design of a slot-loaded low-profile wideband microstrip patch antenna", Microwave \& Opt. Tech. Lett., vol. 62, pp. 1374-1379, 2020.

[13] W. An, Y. Li, H. Fu, J. Ma, W. Chen, and B. Feng, "LowProfile and Wideband Microstrip Antenna With Stable Gain for 5G Wireless Applications", IEEE Antennas Wireless Propag. Lett., vol. 17, pp. 621-624, 2018.

[14] H. X. Lu, F. Liu, M. Su, and Y. A. Liu, "Design and analysis of wideband U-slot patch antenna with U-shaped parasitic elements," International Journal of RF and Microwave Computer-Aided Engineering, vol. 28, Is. 2, e21202, 2018.

[15] [S. Wang, H. W. Lai, K. K. So, K. B. Ng, Q. Xue, and G. Liao, "Wideband Shorted Patch Antenna With a Modified Half USlot", IEEE Antennas Wireless Propag. Lett., vol. 11, pp. 689692, 2012.

[16] T. H. Jang, H. Y. Kim, I. S. Song, C. J. Lee, J. H. Lee, and C. S. Park, "A Wideband Aperture Efficient 60-GHz Series-Fed E-Shaped Patch Antenna Array with Copolarized Parasitic Patches", IEEE Trans. Antennas Propag., vol. 64, pp. 55185521, 2016.

[17] Y. Ge, K. P. Esselle, and T. S. Bird, "A Compact E-Shaped Patch Antenna With Corrugated Wings", IEEE Trans. Antennas Propag., vol. 54, pp. 2411-2413, 2006.

[18] H. Elsadek, and D. M. Nashaat, "Multiband and UWB VShaped Antenna Configuration for Wireless Communications Applications", IEEE Antennas Wireless. Propag. Lett., vol. 7, pp. 89-91, 2008.

[19] W. Lin, and H. Wong, "Wideband Circular-Polarization Reconfigurable Antenna with L-Shaped Feeding Probes", IEEE Antennas Wireless Propag. Lett., vol. 16, pp. 2114-2117, 2017.

[20] K. M. Mak, H. W. Lai, and K. M. Luk, "A 5G Wideband Patch Antenna With Antisymmetric L-shaped Probe Feeds", IEEE Trans. Antennas Propag., vol. 66, pp. 957-961, 2018

[21] S. Bhunia, D. Sarkar, S. Biswas, P. P. Sarkar, B. Gupta, and K. Yasumoto, "Reduced size small dual and multi-frequency microstrip antennas", Microwave \& Opt. Tech. Lett. vol. 50 , pp. 961-965, 2008 .

[22] H. K. Kan, R. B. Waterhouse, A. Y. J. Lee, and D. Pavlickovski, "Dual-frequency stacked shorted patch antenna", Electron. Lett. vol. 41,pp. 624-626, 2005

[23] J. Wu, X. Ren, Z. Wang, and Y. Yin, "Broadband Circularly Polarized Antenna With L-shaped Strip Feeding and ShortingPin Loading", IEEE Antennas Wireless Propag. Lett., vol. 13 pp. 1733-1736, 2014

[24] T. Fujimoto, and S. Fukahori, "Broadband dual-band stacked square microstrip antenna with shorting plates and slits", IET Microw. Antennas Propag. Vol. 6, pp. 1443-1450, 2012.

[25] K. Klionovski, and A. Shamim, "Physically Connected Stacked Patch Antenna Design With 100\% Bandwidth", IEEE Antennas Wireless Propag. Lett., vol. 16, pp. 3208-3211, 2017.

[26] M. A. Matin, B. S. Sharif, and C. C. Tsimenidis, "Probe fec stacked patch antenna for wideband applications", IEEE Trans. Antennas Propag., vol. 55, pp. 2385-2388, 2007.

[27] Z. Yang, K. C. Browning, and K. F. Warnick, "High-Efficiency Stacked Shorted Annular Patch Antenna Feed for Ku-Band
Satellite Communications", IEEE Trans. Antennas Propag., vol. 64, pp. 2568-2572, 2016.

[28] B. L. Ooi, S. Qin, and M. S. Leong, "Novel design of broadband stacked patch antenna", IEEE Trans. Antennas Propag. Vol. 50, pp. 1391-1395, 2002

[29] X. Yang, L. Ge, J. Wang, and C. Y. D. Sim, “A Differentially Driven Dual-Polarized High-Gain Stacked Patch Antenna", IEEE Antennas Wireless Propag. Lett., vol. 17, pp. 1181-1185, 2018.

[30] A. Agarwal, and A. Kaur, "A dual band stacked aperture coupled antenna array for WLAN applications", Microwave \& Opt. Tech. Lett., vol. 59, pp. 648-654, 2017.

[31] C. Y. Chiu, C. H. Chan,, and K. M. Luk, "Study of small wideband patch antenna with double shorting walls", IEEE Antennas Wireless. Propag. Lett., 3, pp. 230-231, 2004.

[32] K. L. Lau, Sai Hoi Wong, and K. M. Luk, "Wideband Folded Feed L-Slot Folded Patch Antenna”, IEEE Antennas Wireless Propag. Lett., vol. 8, pp. 340-343, 2009.

[33] C. Y. Chiu, H. Wong, and C. H. Chan, "Study of small wideband folded-patch-feed antennas", IET Microw. Antennas Propag., vol. 1, pp. 501-505, 2007

[34] M. N. Shakib, M. T. Islam, and N. Misran, 'Stacked patch antenna with folded patch feed for ultra-wideband application', IET Microw. Antennas and Propagation, 4, Iss.10, pp. 1456 $1461,2010$.

[35] Y. H. Lee, E. H. Lim, F. L. Bong, and B. K. Chung , "BowtieShaped Folded Patch Antenna With Split Ring Resonators for UHF RFID Tag Design", IEEE Trans. Antennas Propag., vol. 67, pp. 4212-4217, 2019.

[36] S. Dentri, C. Phongcharoenpanich, and K. Kaemarungsi, "Single-fed broadband circularly polarized unidirectional antenna using folded plate with parasitic patch for universa UHF RFID readers," International Journal of RF and Microwave Computer-Aided Engineering, vol. 26, Is. 7, pp. 575-587, 2016.

[37] N. George and B. Lethakumary, "A compact microstrip antenna for UWB applications", Microwave \& Opt. Tech. Lett. vol. 57, pp. 621-624, 2015

[38] A. E. Taha, A. J. Daniya, and H. H. Mohammed "novel miniaturized folded UWB microstrip antenna-based metamaterial for RF energy harvesting", Microwave \& Opt. Tech. Lett., vol. 33, pp. 621-624, 2020.

[39] A. De, B. Roy, and A. K. Bhattacharjee, "Design and investigations on a compact, UWB, monopole antenna with reconfigurable band notches for 5.2/5.8 GHz WLAN and 5.5 GHz WiMAX bands", International Journal of communication systems, vol. 33, pp. 1-13, 2020.

[40] T. Ali, M. S. AW, R. C. Biradar, A. Andújar, and J. Anguera, "A miniaturized slotted ground structure UWB antenna for multiband applications ", Microwave \& Opt. Tech. Lett., vol 60, pp. 2060-2068, 2018.

[41] H. Wong, K. K. So and X. Gao, "Bandwidth enhancement of a monopolar patch antenna with V-shaped slot for car-to-car and WLAN communications," IEEE Trans. Vehicular Tech., vol. 65, no. 3, pp. 1130-1136, Mar. 2016.

[42] Y. G. Rabobason, G. P. Rigas, S. Swaisaenyakorn, B Mirkhaydarov, B. Ravelo, M. Shkunov, P. R. Young and N. Benjelloun, "Design and synthesis of flexible switching $1 \times 2$ antenna array on Kapton substrate", Eur. Phys. J. Appl. Phys (EPJAP), Vol. 74, No. 3, pp. 1-10, June 2016.

[43] [Y. G. Rabobason, G. P. Rigas, S. Swaisaenyakorn, B Mirkhaydarov, B. Ravelo, M. Shkunov, P. R. Young and N. Benjelloun, "Design of flexible passive antenna array on Kapton substrate", Progress In Electromagnetics Research (PIER) C, Vol. 63, pp. 105-117, 2016. 